\title{
Mística e secularidade: impossível afinidade?
}

\author{
Mystique and secularity: impossible affinity?
}

\author{
Maria Clara Lucchetti Bingemer*
}

\begin{abstract}
Resumo
A religião em seu sentido autêntico e preciso está desaparecendo? Certamente, está ao menos mudando sua configuração. A secularidade ocupa os espaços antes destinados à religião. Neste exato contexto é que, a nosso ver, a mística emerge com redobrada e renovada importância, mas igualmente reconfigurada. Para Panikkar, só o místico pode sobreviver na sociedade atual sem se tornar violento ou cínico. Só o místico pode conservar a integridade do seu ser, porque está em comunhão com toda a realidade. O termo "mística" indica uma relação direta com o mistério, como fonte primeira do ser, de todo o existente passado, presente e futuro, sem tempo e sem espaço, perceptível à interioridade, que contém toda a realidade na sua plenitude. Por isso é algo constitutivamente humano e não necessariamente ligado a uma instituição religiosa ou não. Neste artigo, procuraremos refletir sobre a desinstitucionalização e destradicionalização que marcam as experiências místicas de hoje, as quais se apresentam muitas vezes à margem ou fora de qualquer religião.
\end{abstract}

Palavras-chave: mistica; ecularização; desinstitucionalização; destradicionalização; experiência; compaixão.

\begin{abstract}
Is it religion in its authentic and precise meaning disappearing? Surely, it is at least changing its configuration. Secularity has occupied the spaces before intended to religion. It is precisely in this exact context that, in our view, Mystique emerges with growing and renewed importance, while it is also reconfigured. For Panikkar, Only the mystic can survive in today's society without becoming violent or cynical. Only the mystic can preserve the integrity of his being because he is in communion with all reality. The term "mystique" indicates a direct relationship with the mystery, as the first source of being and also source all the existing past, present and future without time and space that is noticeable to interiority and which contains all reality in its fullness. So mystique is constitutively something human and not necessarily linked to a religious institution. In this paper we reflect on deinstitutionalization and detraditionalization that have marked the mystical experiences of today that are often on the margins or outside of any religion.
\end{abstract}

Keywords: mysticism; secularization; deinstitutionalization; detraditionalization; experience; compassion.

\footnotetext{
Artigo recebido em 21 de julho de 2014 e aprovado em 17 de setembro de 2014.

* Doutora em Teologia Sistemática. Professora na Pontifícia Universidade Católica do Rio de Janeiro. País de origem: Brasil. E-mail: agape@puc-rio.br.
} 


\section{Introdução}

Na sociedade atual se pode dizer que a verdadeira religião, em seu sentido autêntico e preciso, está desaparecendo. ${ }^{1} \mathrm{Ou}$ ao menos mudando de configuração. Neste exato contexto é que, a nosso ver, a mística emerge com redobrada e renovada importância, mas igualmente reconfigurada.

Segundo Ramon Panikkar, teórico e sobretudo experimentador do mistério e, portanto, uma autoridade em mística, só o místico pode sobreviver na sociedade atual sem se tornar violento ou cínico. Só o místico pode conservar a integridade do seu ser, porque está em comunhão com toda a realidade.

Uma expressão como essa diz toda a urgência de uma temática muito fácil e freqüentemente relegada ao âmbito de zona reservada a poucos eleitos, inatingível pelos simples mortais. O termo "mística" indica uma relação direta com o mistério, como fonte primeira do ser, de todo o existente passado, presente e futuro, sem tempo e sem espaço, perceptível à interioridade, que contém toda a realidade na sua plenitude.

A experiência mística pode ser considerada uma atitude do espírito orientada para a união com o Absoluto, pela qual o místico aspira ardentemente, e é geralmente caracterizada por uma série de elementos, incluindo a ilogicidade, a renúncia às paixões mundanas, o êxtase, a inefabilidade. ${ }^{2}$

Neste texto pretendemos primeiramente caracterizar a secularidade e o lugar do ser humano dentro dela. Em seguida procuraremos caracterizar a experiência mística como experiência constitutivamente humana, que acontece no bojo da própria secularidade entendida como ausência de Deus. Faremos-nos ajudar aí da reflexão filosófica do pensador judeu Emmanuel Levinas. Continuaremos aprofundando os contornos da experiência mística em meio à

\footnotetext{
${ }^{1}$ Entendemos a exprressão "verdadeira religião em seu sentido autêntico e preciso" como aquilo que normalmente se entende por religião em termos de definição conceitual, ou seja, um sistema organizado de comunicação (re-ligação) com a transcendência, constituído por um sistema ritual, um corpo doutrinal e um conjunto de normas morais.

${ }^{2}$ Cf. sobre as características da experiência mística nosso livro: BINGEMER, M. C. O mistério e o mundo. Rio de Janeiro: Rocco, 2013. Seguimos aqui parte da reflexão que ali desenvolvemos mais extensa e profundamente.
} 
secularização e à pluralidade que marcam a sociedade de hoje. Estes passos primeiros nos levarão a duas constatações, que constituirão então as duas seções seguintes: a primeira é a da desinstitucionalização e destradicionalização que marca as experiências místicas de hoje, que se apresentam muitas vezes à margem de qualquer religião. A segunda é a ligação estreita e indissolúvel entre mística e compaixão, ou seja, a conexão íntima e iniludível entre experiência mística e solidariedade com a dor humana. Uma vez percorrido esse itinerário, chegaremos então a nossa conclusão, que se empenha em revelar a mística como experiência de amor e não necessariamente religiosa.

\section{1 humano autônomo em um espaço secular}

A modernidade da qual a secularização é parte importante caracteriza-se por estar toda ela marcada por um novo paradigma: o paradigma antropocêntrico. Enquanto na Idade Média, Deus era a medida de todas as coisas, na modernidade, o ser humano é esta medida. O célebre desenho de Da Vinci, do Homem Vitruviano3 descreve bem essa concepção. Atribui-se a Leonardo, com este desenho, a intenção de comunicar sua concepção do mapa do corpo humano como uma cosmografia del minor mondo, na medida em que acreditava que o corpo humano poderia ser considerado uma analogia do universo (GORMAN, 2002).

O paradigma antropocêntrico permitirá a todas as áreas do conhecimento e, muito especialmente, à reflexão sobre a fé que é a teologia, realizar um verdadeiro giro copernicano, partindo do ser humano, de sua realidade e contexto, de sua condição, a fim de falar de modo inteligível sobre a Transcendência, a religião e os mistérios divinos ao mundo moderno e a pessoas moldadas e configuradas pelo crivo da modernidade e da secularização. 4 Mas também trará, em grande parte

\footnotetext{
${ }^{3}$ Desenho famoso do arquiteto Vitruvius que o artista fez ao redor do ano 1490 em um de seus diários. Trata-se de uma figura masculina desnuda separadamente e simultaneamente em duas posições sobrepostas com os braços inscritos num círculo e num quadrado.

${ }^{4}$ Sobre isso as constatações que se faz nos manuais de Introdução à Teologia, ao analisar o método teológico anterior e posterior ao Concílio. Cf., por ex., BOFF, 1998 e também (LIBANIO; MURAD, 1996).
} 
devido ao diálogo com a antropologia não informada pela fé, a transformação de uma concepção de ser humano que, para afirmar-se a si mesmo como ser livre e responsável por seu destino, deve afastar-se de toda e qualquer tutela, sobretudo da religiosa.

A fragmentação do moderno na dificilmente definível pós-modernidade vai re-situar e re-colocar o problema e a interpelação de forma distinta. O momento atual implica em que, no meio da secularização e pluralidade religiosa, em meio à fragmentação mesma da pós-modernidade, o ser humano redescobre o primado da alteridade e revaloriza a experiência dessa mesma alteridade. E a partir disso, redescobre-se como ser relacional, só inteligível para si mesmo a partir da relação. Alguns filósofos modernos centraram sua reflexão sobre a autonomia vista como a capacidade de decisão soberana e solitária do indivíduo em decidir seu destino, sem recurso a nenhuma outra fonte de influência. Em alguns, esta lógica chegou a anatematizar a alteridade como uma ameaça à felicidade humana. Não é possível esquecer, por exemplo, o clamor de Jean Paul Sartre, pela boca do personagem Garcin, na peça “Huis Clos”: "O inferno são os outros!” (SATRE, 1975).

No entanto, outros filósofos contemporâneos desse tipo de concepção do ser humano seguem linha totalmente oposta. Um deles é Emmanuel Levinas, que claramente opta pela responsabilidade pelo outro como a base para uma sociedade humana. Essa se construiria a partir da base transcendental que para ele consiste na epifania do Rosto do Outro. É apenas aí que se instaura a relação Eu-Outro que terá como fruto uma lei racional e uma estrutura política como garantia de liberdade que "pressupõe"que cada indivíduo entra livremente em relação com os outros de tal maneira que a lei e a estrutura se tornem possíveis. Mas essa relação, esse diálogo com o outro é essencialmente caracterizado pela configuração absoluta da relação ética que é a relação "por excelência"para Levinas (LEVINAS, 1994, p. 267; p. 270). Não admira que seja o mesmo Levinas aquele que proclama a Ética como filosofia primeira (LEVINAS, 1998). 
Levinas vai assim, através de sua reflexão, até uma inversão radical do “cogito"cartesiano, afirmando que ser humano é permanecer sob a acusação do Rosto de outro. Desta forma a subjetividade humana se inverte do nominativo "Eu"para o acusativo "me". Não posso, em meu ego antes auto-suficiente e violento, conceber-me mais como princípio (archè), medida de todas as coisas, mas estou eu mesmo colocado em questão e medido, pelo Outro, pelo rosto do Outro que me julga (LEVINAS, 1974, p. 140).

O antropocentrismo moderno, com toda a importância de sua contribuição em termos de pensar o ser humano como liberdade não mais sujeita a leis externas e estranhas a sua subjetividade e sua dignidade de imagem de Deus, corre, no entanto o risco de reduzir-se a uma solidão individualista e atrofiante.

A objetividade do mundo - fruto da modernidade - é a resultante extrema da separação do ser humano da crença em Deus institucionalizada, separação que por sua vez liberta o ser humano e o institui sujeito de seu conhecimento, tornando-o autônomo diante da inteligência e da normatividade divina. Deus - ou a Transcendência - "retirou-se" do mundo, deixando o ser humano entregue a seu esforço e sua busca de sentido.

Por sua parte, o fim do humanismo antropocêntrico (com suas perversas derivações androcêntricas e etnocêntricas) abre caminho a uma visão nova, a uma percepção nova - que se tornaria em conseqüência, uma experiência nova - de uma humanidade que sobreviveu à queda das utopias e à mudança de paradigmas e sente emergir dentro de si o desejo do encontro com a Alteridade Transcendente, que a razão não dá conta de explicar nem circunscrever (BINGEMER, 2005b, cap. 1).

Caberia perguntar- se em que medida se pode falar de experiência real de Deus "sem saber que é a Deus a quem experimentamos" (RUIZ DE LA PEÑA, 1991, p. 398). Em se tratando dessas experiências (experiências de auto transcendência não religiosa), jamais a experiência de Deus permitiria ao ser humano fazer a Deus 
objeto direto de um ato de conhecimento ou de desejo. A diferença entre estas experiências e as mais altas experiências místicas não está em que em umas se conhece a Deus e em outras não, mas sim no fato de que, sendo ambas experiências humanas - como sempre o são - que têm sua origem na Presença fundante que constitui o ser humano, sejam vividas desde o consentimento a esta origem e fonte ou então desde a referência aos apelos da humanidade e sua necessidade e sofrimento. Ou ainda desde a autossuficiência e a referência exclusiva ao próprio eu. As experiências transcendentes assim acontecidas se diferenciam igualmente pelo fato de que sejam interpretadas à luz mais ou menos clara e expressa desse reconhecimento de sua fonte ou cidadania nesta ou naquela instituição religiosa ou então evocando de forma mais ou menos vaga alguma transcendência, ou ainda recorrendo a explicações naturais: psicológicas ou de outra ordem, que as reduzam a experiências meramente humanas. (VELASCO, 1994, p. 87). Na interpretação da experiência está, portanto, a chave de sua identidade.

Em situações culturais como a atual, na qual à secularização da sociedade e da cultura sucedeu a tendência de muitas pessoas a interpretar sua própria vida independentemente da referência à religião, é muito freqüente uma situação pessoal que se deseja totalmente nova em relação à experiência de Deus. Com efeito, muitos de nossos contemporâneos, desligados de toda filiação religiosa, vivem sua vida sem referi-la em nada aos símbolos e categorias com que se interpretam os sujeitos religiosos. Estariam essas pessoas condenadas à carência absoluta de toda experiência de Deus? Não nos parece que se possa chegar a esta conclusão. Concluímos, igualmente, que o ser humano não se compreende sem a abertura e a referência ao infinito, e, portanto esta referência não falta somente pelo fato de que não seja "identificada". Somente uma análise das experiências que algumas pessoas fazem pode mostrar que muitas delas, que ignoram ou recusam-se a designar como Deus a realidade transcendente, reconhecem, igualmente, em determinados âmbitos da experiência humana a presença de uma realidade indizível que se impõe ao humano e que sela uma determinada orientação em sua vida. 
Assim sucede, por exemplo, quando essa pessoa humana se encontra ante valores cuja dignidade não pode deixar de reconhecer, ou quando se enfrenta com ações que, por mais vantagens que lhe tragam, lhe impõem um interdito ético absoluto, e com outras que, por mais inconvenientes que lhe tragam, se lhe impõem se quer viver de forma digna e em paz consigo mesmo. Em tais situações realiza o ser humano um ato de transcendência que o leva a reconhecer no Bem que se lhe impõe uma realidade absoluta. E situações análogas de reconhecimento do Absoluto podem produzir-se, no terreno próprio da filosofia, na experiência do ser e de seu desvelamento na verdade, assim como no da experiência estética, além da relação de respeito e de amor ao outro.

É evidente que tais experiências apresentam uma clara diferença fenomenológica entre si e em relação à experiência religiosa ou eclesial de Deus. Mas a semelhança estrutural, quanto ao que constitui o momento central da experiência religiosa - seu movimento de transcendência, seu radical descentramento -, parece ser uma constante em todas, mesmo não referidas a uma religião institucionalizada. De fato, pode-se legitimamente falar de fé filosófica e teísmo moral para designar algumas delas. $\mathrm{E}$ o fato de que as outras religiões ou mesmo outras ideologias - incorporem a experiência ética e o amor aos outros, como critério de autenticidade da humanidade e, portanto, de toda transcendência, parece indicar que através delas o homem secularizado pode estar encaminhando-se em direção ao mesmo termo absoluto que o homem religioso identifica como Deus. Ou seja, ainda que sob uma forma não religiosa, o homem secularizado pode estar fazendo uma experiência de Deus. 5

O processo de secularização e a queda da hegemonia do cristianismo histórico fizeram com que a reflexão sobre a mística se voltasse não apenas para a reflexão da religião como fenômeno antropológico, tal como o faz Rudolf Otto, ou para a reflexão da religião como aliada às diferenças culturais, como Mircea Eliade

\footnotetext{
${ }^{5} \mathrm{Na}$ teologia cristã, há um ilustre precedente desta tese, com a categoria cunhada por K. Rahner de "cristãos anonimos". (RAHNER, 1996, p. 535).
} 
(1962, 1963, 1959, 1982). Mas também contribuiu para, na medida em que se pensa a religião enquanto plural, poder perceber na experiência mística que acontece no interior desta religião tendências inter e mesmo transreligiosas, que explodem as fronteiras cuidadosamente guardadas das tradições e reafirmam o caráter universal da experiência de Deus.

Gerschom Scholem, pensador judeu, insiste em que "não há misticismo tal qual, há apenas o misticismo de um determinado sistema religioso, cristão, islâmico, judeu e assim por diante.” (SCHOLEM, 1961; MC GINN, 1992, p. 334, n. 48). Além dessa particularização, Scholem recusa-se a restringir o misticismo à experiência de união com Deus... Ele enfatiza que "o misticismo é um estágio definido no desenvolvimento histórico da religião e faz seu aparecimento sob certas condições bem definidas” isto é, durante momentos particulares na evolução da consciência religiosa (SCHOLEM, 1961; 1967, p. 1-24).

Scholem, além disso, ousa uma visão mais matizada e dialética da relação entre mística e sociedade. Diz ele: “Toda mística tem dois aspectos contraditórios ou complementares: um conservador, o outro revolucionário"(SCHOLEM, 1988, cap. 1). O místico deve falar a linguagem da tradição para ser entendido, mas assim fazendo, ela ou ele se vê confrontado com certas escolhas e problemas. Enquanto o místico identifica a fonte da comunicação mística com a revelação original que está na base da tradição, o misticismo , quando institucionalizado, pode servir como força conservadora, renovando e reforçando aquilo que a tradição geralmente fez. 6

Com todo o respeito que nos merece o pensamento de G. Scholem, concordamos com sua segunda afirmação, mas não tanto ou totalmente com a primeira. E mais do que nunca, hoje em dia, temos o exemplo de místicos que viveram uma experiência de união com o absoluto sem estar filiados a nenhuma religião, mesmo a sua de procedência. ${ }^{7}$

\footnotetext{
${ }^{6}$ Scholem $(1988$, p. 11, 27-29) se refere aqui especificamente ao judaísmo, mas cremos que sua afirmação pode estender-se a qualquer religião, onde Scholem identifica três pontos auxiliares para a identificação da fonte. Cf. o comentário de MC GINN, 1992, p. 335 , n. 55. ${ }^{7}$ Por exemplo, a judia Etty Hillesum (1995), que vive uma extraordinária experiência mística, mas que não pode ser referida a nenhuma religião, sequer a seu judaísmo de origem. Cf. seu diário e cartas (HILLESUM, 1995).
} 
Certa configuração do que em teologia chamamos "fé" parece ir desaparecendo paulatinamente, mas consistentemente, sobretudo das sociedades mais afetadas pela urbanização e conseqüentemente pela secularidade. O fenômeno da incredulidade - que poderia ser definido como não crença na religião institucionalizada - nasce a partir do anseio por liberdade de pensamento e ação e conota, portanto, uma secularização da espiritualidade. Neste ponto o filósofo André Comte-Sponville, em sua obra O Espírito do Ateísmo - onde ao mesmo tempo em que se declara não crente afirma já haver vivido profundas experiências de transcendência - declara que a espiritualidade desta época secular é a ética humanista. 8

Em meio à profanidade do mundo e ao espírito do século se percebem, portanto, experiências que podem ser alinhadas entre o que entendemos por experiências do mistério, ao qual desde a fé, chamamos Deus. Um Deus, porém, que não é nomeado nem muito menos identificado como uma pessoa. Mas que nem por isso é menos ou menos concretamente, existente sob a forma pluriforme do que entendemos por Transcendência e que é constitutiva do ser humano.

\section{Mística em meio à profanidade do mundo e ao silêncio de Deus}

A partir do que vimos acima, emerge uma pergunta: O mundo secular seria realmente um mundo sem Deus ou do qual Deus se teria ausentado? Uma das pretensões da modernidade foi retirar a questão de Deus do horizonte da humanidade. Tentando defini-la, se disse que a secularização é justamente o processo, ativo ou passivo, do retorno ao "saeculum”, ou seja, ao mundo profano, de uma realidade que estava estreitamente ligada a Deus e à religião. 9

\footnotetext{
${ }^{8}$ Outros teriam certamente outras definições, tais como a comunhão com o cosmos, a busca de estados alterados de consciência, etc. Citamos Comte-Sponville (2006) não apenas por sua indiscutível autoridade intelectual como também por nos parecer um exemplo bastante pertinente do contexto hodierno.

${ }_{9}^{9}$ Os inúmeros autores que trabalham esse aspecto da secularização como mudança de prisma para compreender e assimilar o religioso. Jurgen Moltmann (1999); V. Westhelle (2000); Jean Yves Lacoste (1998); Macmillan Publishing Company (1987); Paul Poupard (1987); Andrés Torres Queiruga (1993; 2000); Derrida; Vattimo (2000); Martelli (1995); Souza (1986a); Souza (1986b); Paul Ricoeur (1976).
} 
A crise da modernidade e sua tardia reconfiguração em uma nova etapa chamada - própria ou impropriamente - pós-modernidade, longe de dar um fim a esse processo, assume suas marcas principais e se propõe radicalizar a "morte" cultural e conceitual de Deus. Ao lado da reaparição do religioso, o ateísmo não desapareceu do horizonte ocidental. E não se trata mais apenas do ateísmo moderno dos mestres da suspeita, seus antecessores e seguidores. Há novos ateísmos que se perfilam no horizonte e que vão questionar em profundidade as instituições religiosas mais tradicionais, sobretudo os três monoteísmos. Não se trata, igualmente, de uma não-religiosidade pura e simples. Ao invés, estamos diante de uma indiferença religiosa que não se preocupa minimamente em dar-se ao trabalho de raciocinar sobre a existência ou não-existência de Deus. ${ }^{10}$

$\mathrm{Na}$ verdade, enquanto o ateísmo moderno negava Deus e afirmava um projeto humano - a morte de Deus seria o preço a ser pago para que finalmente surgisse e se desenvolvesse plenamente a autonomia e a liberdade humanas - o ateísmo contemporâneo pós-moderno e a indiferença religiosa ameaçam expulsar de uma só vez não só a Deus, mas também o humano, questionando a consistência e a existência mesma dos fundamentos da sociedade e da globalidade do real tal como configurados no ocidente.

O pensamento pós-moderno, caracterizado pela "desconstrução" e relativização de todo o edifício conceitual aparentemente sólido da modernidade, questiona também toda tentativa de dizer o Absoluto inefável que os cristãos e outras tradições religiosas chamam Deus; considera todo discurso com pretensões à universalização e à totalização como redutor e inadequado e desemboca na indiferença e no desencantamento. E, agindo assim, abre para o pensamento e o discurso cristãos uma pista aparentemente nova, mas em verdade muito antiga, que desemboca no mistério e na pluralidade, como confissão de impossibilidade de

\footnotetext{
${ }^{10}$ Cf as obras recentes sobre o ateísmo contemporâneo, tais como: B. Forte (1999); Maria Clara Bingemer (1990). Cf. igualmente as obras recentes dos assim chamados "novos ateus": Sam Harris (2008); F.S.Collins (2007); Christopher Hitchens (2007); Richard Dawkins (2007); Michel Onfray (2007).
} 
pensar e de dizer consistentemente o Ser, qualquer que seja a dimensão na qual se pretenderia compreende-lo. ${ }^{11}$

A isto se segue que, não somente a razão e a reflexão, mas ainda o desejo e a sede de infinito e de transcendência se encontram acuados numa aporia que poderia ter um reverso feito de fé, de confiança, de surpresa maravilhada diante do Mistério. E isto poderia ter por efeito - ainda que invertido e paradoxal - que a experiência e o discurso sobre Deus encontrassem, por estes tempos que pareceriam à primeira vista tão hostis, uma possibilidade não imaginada de fecundidade.

Com efeito, o projeto da modernidade engendrou a indiferença religiosa mais do que a negação de Deus. E ao mesmo tempo a crise deste projeto demonstrou que uma sociedade, se não encontrar seu fundamento em uma Transcendência - seja dado a ela ou não o nome de Deus - se dissolverá lenta e inexoravelmente. Em suma, se o ateísmo - entendido em termos modernos continua a ser uma questão que é colocada quando se faz menção do problema de Deus, é preciso ainda reconhecer que ela não é mais a única. Mais: talvez se possa mesmo reconhecer este ateísmo como presença não de todo negativa na cultura moderna e pós-moderna. Esta se encontra, de fato, diante do silencio do Deus da tradição pré-moderna e desafiada a descobrir uma nova imagem de Deus que emerge do mundo secular e plural. No fundo, seria possível encontrar uma concepção de Deus que evoluiu de uma concepção de Deus pessoal - tal como a pré-modernidade a propunha - em direção a um Deus mais impessoal e, portanto, mais afastado da tradição cristã (MARDONES, 2005, p. 34). Mas não estaria aí para o homem e a mulher pós-modernos a fascinante oportunidade de descobrir aquele que desde a primeira hora da nossa era, Paulo de Tarso tentava anunciar aos

\footnotetext{
${ }^{11}$ Cf. As inúmeras obras que se detêm na análise deste fenômeno: Jacques Dupuis (1999); F. Teixeira (1995); F. Teixeira (2000); Monique Hebrard (1997); Leila Amaral (1994); Jean Louis Schlegel (1985).
} 
atenienses, procurando o caminho para nomear o Deus desconhecido cujo templo encontrara andando pela cidade? ${ }^{12}$

O grande teólogo Karl Rahner afirma que Deus é constitutivo do ser humano, em sua identidade em contínua autotranscendência. ${ }^{13}$ "Ela (a palavra 'Deus') está sempre exposta ao protesto de Wittgenstein, que manda guardar silêncio sobre o que não se pode falar com clareza, mas que infringe essa máxima pelo próprio fato de expressá-la. A palavra mesma, se bem entendida, concorda com essa máxima. Pois ela é a última palavra antes do silêncio que emudece sem palavras em adoração perante o mistério inefável” (RAHNER, 1989, p. 178, grifo nosso).

Apenas o desejo que às vezes emudece pela impossibilidade de dizer-se está apto a qualificar a relação de Deus com o ser humano; mas por outro lado, a relação estabelecida por este desejo situa o homem diante da "diferença" mesma de Deus. É então o ser humano que, na experiência, é tomado pela transcendência e pelo mistério e não o contrário. E sua experiência, se ela é verdadeira, escapa inteiramente ao seu domínio e controle. (MORANO, 2001).14

Se, portanto a experiência de Deus se produz ao nível do desejo - não podendo se produzir de outra maneira - é preciso também dizer que ela se produz enquanto mistério. Não há transição natural e lógica entre a experiência cotidiana da vida e a experiência de Deus, ainda que esta seja o lugar do advento daquela. É permitido falar de um conhecimento analógico, partindo da percepção fundamental de que nada, nenhuma realidade, é capaz de exprimir a transcendência. Portanto, com respeito a toda experiência humana de

\footnotetext{
${ }^{12}$ Cf. At 17,1ss o famoso episódio de Paulo no Areópago de Atenas.

13 "não temos nenhuma experiência de Deus do tipo da que temos de uma árvore, de outra pessoa humana ou de outras realidades externas que, embora talvez nunca existam para nós simplesmente sem palavras, contudo por si mesmas forçam o nascimento de uma palavra sobre elas porque simplesmente surgem no âmbito de nossa experiência em determinado ponto do espaço e do tempo e, assim, por si mesmas, elas impulsionam imediatamente a que se lhes dê um nome. Podemos, portanto, dizer que o que existe de mais simples e iniludível para o homem com respeito à questão de Deus é que a palavra 'Deus' existe em sua vida espiritual e intelectual". $E$ continua: se alguém quisesse evitá-la "não só teria de esperar que na existência do homem e na linguagem da sociedade desaparecesse por completo, mas também deveria contribuir para este desaparecimento guardando completo silêncio, abstendo-se de se declarar ateu. Mas como poderia fazê-lo se outros, de cujo campo lingüístico não pode definitivamente emigrar, continuam a falar de Deus e se preocupam com essa palavra?" (RAHNER, 1989, p. 178).

${ }^{14}$ As obras mais recentes de Morano (2001), ainda não traduzidas ao português. Cf. igualmente nosso livro BINGEMER, 1993.
} 
transcendência, o termo mistério é aquele que convém melhor para definir a descoberta do Absoluto - nomeado ou não, reconhecido ou não - que atrai e convida à experiência. ${ }^{15}$

O silêncio é o companheiro da experiência e da compreensão íntima que do mistério se tem ou pode ter, experimentando-o. É a possibilidade real do ser humano gozar e enfim perceber a insuficiência das palavras e dos conceitos para expressá-lo, calando-se para possuí-lo realmente. Há um mistério de morte imanente à consciência e à linguagem humana quando se trata de dizer a experiência como possibilidade de conhecer o Absoluto. Isto é reconhecer que tudo começa antes da humanidade e que esta não chega, de uma maneira ou outra, senão "posteriormente", demasiado tarde para ser totalmente pertinente ao Mistério e colocar-se em relação plena com ele. ${ }^{16}$

\section{Experiência de Deus entre a secularização e a pluralidade}

Nossa época, portanto, pode ser percebida como um momento histórico onde a experiência voltou com força à frente da cena e ao coração do conhecimento e do debate. Sobretudo nas últimas quatro décadas, após maio de 1968, quando a revolução sexual foi oficializada e era importante "fazer amor e não guerra".17 $\mathrm{O}$ movimento hippie e todos os outros movimentos libertários que aí tomaram o primeiro plano dos acontecimentos diziam, em síntese: “É necessário experimentar tudo. E não é obrigatório decidir-se por nada.” (GONZALEZ BUELTA, 2010).18

\footnotetext{
${ }^{15} \mathrm{O}$ texto de K. Rahner (1967) diz que "O homem - quer o afirme expressamente ou não o afirme, quer reprima esta verdade ou a deixe aflorar à superfície - se acha sempre exposto, em sua existência espiritual, a um mistério sagrado que constitui o fundamento de sua existência. Este mistério é o mais primitivo, o mais evidente, mas por isso também o mais oculto e ignorado; um mistério que fala enquanto guarda silêncio, que "está aî" enquanto que, ausente, reduz a nossas próprias fronteiras. E todo isso porque, como horizonte inexprimível e inexpressado, abrange e sustenta sem cessar o pequeno círculo de nossa experiência cotidiana, cognitiva e ativa, o conhecimento da realidade e o ato da liberdade. Nós o chamamos Deus." (RAHNER, 1967).

${ }^{16}$ Cf. o recente filme "O grande silêncio", sobre a vida na Cartuxa, filmado por Philip Gröning que, para fazê-lo, internou-se seis meses na Cartuxa de Grenoble, França.

${ }^{17}$ Referimo-nos ao "slogan", lançado pela canção de John Lennon e utilizado no movimento que nos anos 70 levantou milhares de manifestantes que se opunham ao envolvimento dos Estádos Unidos da América na guerra vietnamita. E que fez que em um pais onde predominava o puritanismo, a "permissividade sexual" tivesse seu auge.

${ }^{18} \mathrm{Cf}$. sobre este ponto a bela e fina análise que faz B. G. Buelta.
} 
$\mathrm{Na}$ verdade, o desejo de experimentar é natural e inato ao ser humano. No entanto hoje ele é estimulado exponencialmente e provocado pela sociedade e pela cultura em que vivemos. O resultado é que esta cultura, de tanto desejar indefinida e infinitamente, sem freios nem critérios de discernimento, transforma-se em uma cultura frígida e estéril. E, logicamente, também esterilizante.

$\mathrm{Na}$ verdade a loucura consumista tem como contrapartida uma perda imensa, que leva a uma obsolescência de tudo que é vital e novo, inclusive os sentidos e o desejo (CAVANAUGH, 2007, p. 148-154). Nesse processo é levada avante uma "ascese" que vai à contra mão da ascese clássica das tradições religiosas e pode tornar-se a grande responsável por algo que corre o risco de configurar-se como a morte do desejo e da vitalidade.

A ascese da vida contemporânea - segundo J. Heissig - é na verdade uma caricatura da mais rígida ascese religiosa clássica. Sua prática é em grande parte inconsciente e isso a torna ainda mais perigosa (HEISSIG, 1996, p. 225). A intensidade do isolamento, a mortificação dos apetites e a frigidez dos sentidos exigidos daqueles que optam por viver no centro do mundo civilizado é melhor medida pela quantidade de sonolência e letargia a que induzem essas coisas do que por qualquer austeridade aflitiva destinada a manter o estado de alerta e de vigília. Longe do ideal de uma disciplina da penitência, essa ascese do cotidiano não é mais do que um sinal exterior de uma aridez interior (HEISSIG, 1996, p. 224).

Como diz J. Heissig, a escolha contra a pobreza e a privação não precisa esperar pela reforma das estruturas sociais (HEISSIG, 1996, p. 225). Pode-se inaugurar uma revolução simples em busca de uma forma de vida igualmente simples e talvez mais satisfatoriamente humana. Uma vida mais simples necessariamente nos estimularia a usar mais os sentidos, e aliviaria boa parte da infélicidade que parece constituir a vida hodierna, quando a depressão é a doença 
do século e o suicídio aumenta exponencialmente nos países em vias de desenvolvimento ${ }^{19}$.

Fazer essa opção hoje implica então para muitos redescobrir a fonte de experiências transcendentes de comunhão com o mistério da vida, que podem, portanto, receber o selo de "místicas", embora não se dêem dentro de qualquer instituição eclesiástica ou religiosa. Pois enquanto a ascese clássica ensinava a disciplinar um corpo que parecia querer sentir e gozar demais, agora a ascese é frequentemente aquela cujo objetivo consiste em reaprender a sentir e a gozar (HEISSIG, 1996, p.225). Reaprender a ouvir os ruídos da natureza e a boa música; a ver a infinita gama de cores das árvores, dos pássaros e do mar; a sentir os odores do primeiro café da manha, do azeite que esquenta na cozinha para preparar o alimento, da terra molhada depois da chuva; a degustar um pão puro, sem manteiga e que alimenta com seu básico trigo, a sorver com delícia um copo de água fresca em um dia de calor; a tocar no pelo do animal de estimação e sentir-lhe a maciez e, mais que mais, tocar no corpo dos seres queridos com abraços, beijos, mãos entrelaçadas, sentindo a comunhão na carne que simboliza a do espírito.

Vivemos em uma cultura em recesso de desejo e sob a ameaça da extinção do mesmo (GUILLEBAUD, 1998, p. 114). Nossas sociedades tão agressivamente erotizadas, onde o erotismo, de tão propalado, banalizou-se e virou mercadoria barata, estão na verdade espicaçadas pela obsessão da ausência de desejo. E essa obsessão que pareceria uma hiper-sexualização na verdade é o contrário mesmo disso (GUILLEBAUD, 1998, p. 114).

J. C. Guillebaud afirma que "esta retórica humanitária aplicada ao desejo testemunha de uma inquietude nova: a de uma lenta emasculação por falta, de uma inexorável nostalgia de desejos que definham" (GUILLEBAUD, 1998, p. 115). E

\footnotetext{
${ }^{19}$ Segundo a Deutsche Welle, a cada 35 segundos, uma pessoa comete suicídio. Apenas na Alemanha, há alguém se matando a cada 45 minutos. A cada dia 40 jovens tentam se matar, mas apenas três conseguem. Suicídios perfazem $2 \%$ de todas as causas mortis no mundo. Os índices de suicídio são maiores nos países industrializados, sendo que proporcionalmente o Leste Europeu possui a taxa mais alta, enquanto em números absolutos a China lidera as estátísticas. Cf LESTE, 2002.
} 
prossegue: "não mais lutar contra a repressão do desejo mas de prevenir sua derrocada retumbante" (GUILLEBAUD, 1998, p. 115).

Não são poucos os pensadores que se debruçaram recentemente sobre esta questão. O próprio Georges Bataille, que longamente refletiu sobre o erotismo (BATAILLE, 2004) reafirmou algo na mesma linha: "No meu entender, a desordem sexual é maldita. Sobre isso, apesar das aparências, eu me oponho à tendência que parece hoje em dia predominar. Não sou dos que vêem no esquecimento dos interditos sexuais uma saída. Penso mesmo que a possibilidade humana depende desses interditos.” (BATAILLE, 2004, p. 16).

Portanto, pretender experimentar tudo pode ser, no final, não experimentar verdadeiramente nada. Sobrevoar muitas coisas, rodear-se de muitas pessoas, caminhar nas beiradas de muitas relações pode não ter como fruto nada consistente e conduzir a uma dolorosíssima e insuportável frustração. As incontáveis sensações que se vão alojando em nossas fomes naturais, ou nas artificiais criadas com habilidade pela sociedade de consumo, em muitas ocasiões vão impondo decisões que não são positivas porque na verdade não são nossas. Provêm de uma exterioridade alheia a nossa própria identidade e a nosso real desejo (GONZALEZ BUELTA, 2010, p. 13).

A ruptura da imanentização materializante e idólatra da sociedade consumista de hoje só parece romper-se se nela se re-introduz a primazia do desejo, constitutivo do sujeito, da pessoa, dando dinamicidade a sua interioridade, ao seu crescimento enquanto pessoa, a sua continua auto-transcendência. Não faz parte do mundo, a não ser na medida em que o sujeito integra o mundo. Trata-se de uma atitude do sujeito em relação ao mundo. É subjetivo e não objetivo. Em suma, o desejo sussurra ao ouvido da pessoa humana, incessantemente, qual é sua condição: ser criado, humano, finito e limitado. Mas capaz de desejar o Ilimitado, o Infinito.

O espaço aberto na subjetividade pelo desejo da transcendência e a abertura para a interioridade, para o Mistério, pode ser a força capaz de romper o obstáculo 
escravizante da materialidade do consumismo. Neste sentido, o movimento para a valorização da interioridade que hoje se percebe no ser humano, chegando a fazer da mesma quase um novo paradigma tem como conseqüência uma crítica e rejeição da sociedade do consumo e da exterioridade de sensações (VELASCO, 2004).

A restauração da capacidade desejante do indivíduo e da sociedade vai na direção contrária, portanto, à corrente da excitação constante das sensações; contra o predomínio de uma emocionalidade "líquida", sem discernimento e sem capacidade decisória; contra o consumo desenfreado como busca da felicidade e contra a redução da pessoa humana a um mero consumidor passivo de produtos que lhe são impostos por tal tipo de sociedade. A volta à interioridade, à contemplação, à meditação - mesmo não religiosa nem institucional - que hoje se percebe constitui, portanto um movimento contracultural (MARDONES, 2005, p. 210).

Recuperar a capacidade desejante é por outro lado e igualmente recuperar os próprios sentidos para aquilo que realmente foram feitos: ver, escutar, sentir, saborear, tocar. Escutar a beleza da música composta sob a inspiração do artista. Mas também escutar os apelos que brotam da própria interioridade, assim como os clamores do próximo por justiça e equidade. Ver a beleza da natureza, das obras de arte, dos seres humanos em tanta diversidade, mas igualmente a realidade doente deste mundo; não fugir da "visão" do sofrimento nem da morte injusta e prematura infligida a tantos e tantas. As espiritualidades de todas as tradições religiosas conduzem para a atenção, a concentração, e não para uma evasão da realidade.

Por isso, dificilmente se pode acusar - como se tentou tantas vezes - a mística e a contemplação de serem práticas alienantes e evasivas. Ao contrário, a verdadeira experiência iluminativa e espiritual abre a sensibilidade e a inteligência do contemplativo para a realidade cotidiana e o exercício da compaixão para com o próximo. Não existe aí fuga para a estratosfera, ou refúgio em uma nebulosa opaca, mas sim retorno à realidade da terra com suas feridas e injustiças. Se a experiência espiritual em si mesma não produz uma capacidade de análise estrutural dos fatos 
injustos ou dolorosos, é inegável que afina a sensibilidade para percebê-los. A partir desta sensibilidade, acrescida pela análise político-estrutural da realidade, aquele ou aquela que experimenta sua interioridade habitada e dilatada pela Transcendência está certamente muito melhor equipado para ter consciência política dos fenômenos sociais e intervir na polis em uma ação transformadora solidária. (MARDONES, 2005, p. 210).

Valorizar a experiência interior - que vai na contra-mão das sensações agressivamente sedutoras e seduzidas -, feita de desejo e emoção de sentimentos discerníveis pela consciência - é tudo menos alienação. A sede da transcendência, sintoma inegável da tardo ou hiper ou pós-modernidade em que vivemos, dá testemunho de que todas as possibilidades do erotismo e do consumo não bastam ao ser humano. Cabe dizer, com M. Gauchet (2004, p. 19), que "se a crítica revolucionária à sociedade burguesa e seu idealismo mentiroso se efetuou sob a bandeira do materialismo, hoje estamos ante um processo crítico-revolucionário que se desdobra sob o estandarte espiritual. Hoje inclusive descobrimos uma grande afinidade de fundo entre ambos." (TOURANIE, 2006; HABERMAS, 1984; DURAND, 1995; MARDONES, 2005).

A experiência com essas características dá origem a um conhecimento. $\mathrm{O}$ conhecimento seria, pois, experiência compreendida e explicada (por meio de uma atividade intelectual), primeiro a si mesmo e depois aos demais. Um conhecimento sem experiência é puro verbalismo, conceito vazio, ilusão (GAUCHET, 2004, p. 27).

Quando o ser humano faz uma experiência do absoluto, do mistério, não encontra na estrutura desta experiência uma linguagem sobre Deus como sobre um objeto entre outros, mas sim um sentido radical que torna possível a existência das múltiplas linguagens que compõem o horizonte interpretativo do ser humano e torna possível, igualmente, uma revelação de algo que ultrapassa a finitude (LABARRIÈRE, 1973, p. 209-223).

A abertura do espírito humano ao Último, ao Derradeiro, ao Sentido Radical da realidade tende, portanto, em seu próprio dinamismo, para um horizonte 
inatingível, para a plenitude do ser e do bem, que mobiliza a inteligência e a liberdade humanas e está presente em cada ato cognitivo ou volitivo como condição de sua própria possibilidade. E isso é constitutivamente humano. Independe de qualquer pertença associativa ou institucional.

\section{Mística e desinstitucionalização}

Porém, hoje, em plena pós-modernidade, - quando a secularização é um fato irreversível e o mundo teocêntrico, no qual a linguagem do religioso institucional se encontrava no centro do saber e sua expressão, ficou definitivamente para trás, - existe um processo de afastamento da instituição eclesiástica que chega a todas as esferas da vida cristã. A experiência mística não escapa a esse processo. Na verdade, quase todos os místicos - cristãos ou não tiveram dificuldades com a instituição religiosa ou secular e a superaram de diferentes maneiras.

É notório que, para além das reafirmações permitidas pela linguagem da "volta da religião" ou "retorno do sagrado" o que vai acontecendo sob nossos olhos é uma mudança na definição do que seja religião. De um lado, assim como hoje os limites do político extrapolam o estado, o que atesta a insuficiência da neutralidade contida na separação entre Igreja e estado para disciplinar a relação entre religião e política; por outro lado, há uma visível desinstitucionalização da religião, que se traduz na proliferação de igrejas, movimentos e grupos informais, que não mais se prendem aos protocolos de autorização ou sanção eclesiástica, bem como à difusão/disseminação do religioso para além das fronteiras reguladas pelas instituições religiosas. O religioso emerge na esteira de um cansaço com a política e com a religião institucionalizadas. E isso ocasiona uma utilização da religiosidade mística ou difusa que caracteriza o ambiente da contemporaneidade, utilizada muitas vezes como terapia de auto-ajuda em nível pessoal; como anti-stress nas empresas; ou como orientação motivacional para grupos os mais diversos. Também ocorre que militantes políticos/sociais busquem o amparo ou consolo da 
religiosidade para renovarem suas energias utópicas ou mesmo recorram a práticas religiosas em substituição à atuação política (BURITY, 2001, p. 27-45).

As experiências religiosas ou espirituais dos indivíduos em boa parte são marcadas por uma significativa autonomia religiosa dos atores, que circulam entre os diversos grupos existentes. Estes constroem em boa medida, por conta própria, sua religiosidade, numa espécie de bricolagem (arranjo pessoal do religioso ou espiritualidade errante, religiões difusas, modelo holístico individual, coexistência de paradigmas) e por um crescente processo de destradicionalização da religião e de desinstitucionalização da identidade religiosa. Dá-se uma crescente subjetivação da religião e uma radicalização da pluralidade religiosa. Esta tende a transcender a dimensão institucional, configurando-se, sobretudo em conformidade com a consciência individual. E a argumentação que se encontra por trás disso vai na direção de uma privatização da experiência religiosa. O divino estaria dentro de cada um de nós, não necessitando da presença da instituição. Haveria simplesmente que desenvolvê-lo.

Estamos, portanto diante de um quadro que se move em torno da busca de auto-aperfeiçoamento e auto-realização, em constante experimentação, que incorpora caminhos próprios tanto para a dimensão espiritual, quanto para a psíquica, a corporal, a intuitiva, tratando de caracterizar-se como uma busca holística. Trata-se de um imbrica mento de terapêutica e de espiritualidade, onde a verdade última é construída e orquestrada pelo próprio sujeito, um experimentador por excelência (SIQUEIRA, 2011).

Assiste-se a um processo de privatização das crenças religiosas e a uma pluralização da fé, chamada com diversos nomes: liberalização religiosa (PACE, 1997); religião difusa (PARKER, 1997); religiosidade ou identidade religiosa flexível-flutuante (HERVIEU-LEGER, 1993); nova sensibilidade místico-esotérica, sacralidade não religiosa, nova religiosidade sincrética (MARDONES, 1994); nebulosa heterodoxa (MAITRE, 1998); nebulosa místico-esotérica e crédulos difusos (CHAMPION, 1990); nebulosa polivalente da Nova Era e diversidade nas formas de adesão (SANCHIS, 1997). 
Estamos, portanto, diante de um processo de desinstitucionalização das religiões históricas e de destradicionalização da religiosidade, a partir da ênfase no presente, nas diferenças, na experimentação, no indivíduo e na ruptura com a noção de representação. Esta destradicionalização tende a ser associada a um póscristianismo, sobretudo a um pós-catolicismo (SANCHIS, 1997). O movimento de desinstitucionalização religiosa ou diluição das fronteiras religiosas e de quebra do monopólio ou da hegemonia do catolicismo, é acompanhado por um processo cada vez mais forte de composição de um pluralismo religioso.

Este estado de coisas também se reflete sobre a mística. Uma das características da mística contemporânea traz consigo esta tendência à desinstitucionalização ou autonomia em relação com a instituição e a autoridade eclesiástica. A experiência espiritual se apresenta de uma maneira nova, mais livre, mais desinstitucionalizada, mais aberta à pluralidade e em diálogo não somente com o ateísmo ou o agnosticismo, frutos da secularização ${ }^{20}$ como também com outras tradições religiosas. ${ }^{21}$

Por outro lado, os místicos, ou seja, os homens e mulheres que viveram uma experiência profunda e visceral de Deus não estão mais recolhidos fora do mundo ou no silencio do claustro. Ao contrário, podem ser vistos nas ruas, "no coração das massas", ativos e participando nos grandes desafios de nosso tempo, ocupados com questões muito "seculares" e inspirados por sua experiência espiritual. ${ }^{22}$ Ao lado disto, muitos, senão quase todos estes místicos foram muito críticos da instituição, apesar de sua falta de dúvidas sobre a autenticidade da própria experiência. Quase

\footnotetext{
${ }^{20}$ Por exemplo, o belo livro de A. COMTE SPONVILLE, L'esprit de l'athéisme, Paris, Cerf, 2006, entre outros.

${ }^{21} \mathrm{Cf}$ por exemplo toda a obra de L. MASSIGNON, 1962. ; v . também a de H. LE SAUX, 1986.

${ }^{22}$ Cf. Raissa Maritain (1995), casada e filósofa, que criou juntamente com seu marido e sua irmã uma comunidade de oração em sua casa, onde se reunia com toda a intelectualidade frances dos anos 30. Madeleine Delbrel (2007), que deixou sua experiencia de trabalhadora para ocupar-se do povo da rua. D. DAY (1993), a mística militante das ruas de Nova York ; E. HILLESUM (2008), jovem advogada cuja experiência mística a levou ao campo de concentração de Westerbrok, a fim de " ajudar a Deus, salvar meu povo e ser um bálsamo para todas as feridas ». Mesmo Thomas Merton, monge trapista, exceção que confirma a regra, foi um tipo de monge original e inesperado, que em seus escritos regulares para a grande imprensa se ocupava de questoes muito atuais de seu pais, os Estados Unidos e que foi um pioneiro no diálogo com a vida monástica budista (Cf. MERTON, 1948). Cf. tb. BERTELLI (2008).
} 
todos também tiveram dificuldades reais com a própria instituição e fizeram seu caminho, por assim dizer," à margem" da mesma. ${ }^{23}$

Esta tensão fundamental entre a "experiência" e a instituição não é nova. O uso da categoria "experiência" sempre foi problemático na teologia católica moderna tanto por causa da notória dificuldade em precisá-lo quanto devido ao fato de experiência sempre ser uma palavra com peso de código para impulsos psicológicos ou estados de consciência subjetivos descritos à custa da claridade doutrinal (McDONNELL, 1997, p. 3-18; CUNNINGHAM, 1998, p. 9).

Isto tem seu impacto igualmente no olhar que desde fora se projeta sobre a mística e sobre as experiências espirituais profundas e transformadoras de homens e mulheres na contemporaneidade. Já não pode ser o único nem o principal critério para avaliar tais experiências a adesão maior ou menor que essas pessoas tenham a sua instituição de pertença ou a qualquer instituição que seja. Não é mais tão vinculante ou imperativo que a experiência de Deus tenha que dar-se dentro dos limites de uma instituição. Pois é notório encontrar experiências que não se pode negar que possuem todas as características de uma experiência mística e se dão fora da instituição ou mesmo à margem da mesma, ou inclusive na ignorância da mesma. Ou seja, em outras palavras, não é obrigatório nem necessário que o místico tenha dificuldades com a instituição e críticas insuperáveis à mesma como é o caso, por exemplo, de Simone Weil e outras (BINGEMER, 2005a, p. 365386) - mas pode dar-se o fato de que jamais nem sequer tenha cogitado em pertencer a nenhuma religião institucionalizada, - como é o caso, por exemplo, de Etty Hillesum (2008, supra nota 17).

Nesse caso, o critério para discernir e afirmar que suas experiências são autênticas será unicamente a fecundidade das mesmas, ou seja, os frutos que sua experiência produzirá em seu ambiente e sobre as outras pessoas. Estes, derramando-se a partir da vida do místico, devem apontar a um reforço e proteção da vida, serviço aos outros e simplicidade e desapego cada vez maiores.

\footnotetext{
${ }^{23}$ Cf. por exemplo, o italiano Ignazio Silone (DANESE; NICOLA, 2007); ou o próprio Emmanuel Mounier $(1961,1968)$.
} 
Uma das características da mística na contemporaneidade, portanto, é o fato da existência de uma sensibilidade que busca a experiência direta com o mistério da Realidade última sem necessariamente a mediação da instituição. Isso parece percorrer todas as religiões e confissões religiosas. Essa busca de experiência direta já não apresenta contornos institucionais nítidos, mas pelo contrário, aponta para uma tendência trans-religiosa, onde o contato buscado se dá com o fundo mais profundo, o segredo último da realidade, que nós chamamos de Deus e que os estudiosos das religiões identificam como o denominador comum, o núcleo de todas as religiões (DUCQUOC, 2002, p. 125).

O sintoma é identificado pelos observadores e estudiosos como uma clara e inegável insatisfação com a religiosidade predominante e institucionalizada. Instaura uma busca mais pessoal e mais experiencial do divino (HEISSIG, 2005, p. 246ss). O risco desse passo, quando dado, sem dúvida alguma é a superficialidade que pode ocorrer quando, em termos espirituais, o ser humano se dispõe a fazer vôo livre, independente de qualquer instancia que o regule e controle, recusando-se a deixar-se guiar por uma instituição.

Por outro lado, há que reconhecer o aspecto extremamente positivo que ai reside: a comprovação da liberdade de Deus, que não se deixa aprisionar por nenhuma instituição, código ou sistema, ainda que religioso. A espiritualidade de nossa época não esperou a reforma das Igrejas ou instituições religiosas para efetuar sua própria busca. Nem muito menos a bênção da academia. Nossos contemporâneos entrecruzam vocabulários, conceitos e símbolos de todas as procedências e cidadanias sem pedir permissão aos representantes acadêmicos ou institucionais (MARDONES, 2005, p. 201-202).

No entender de alguns teólogos, trata-se de uma rara oportunidade para que o estudo das religiões possa redescobrir o estatuto místico da fé. E assim fazendo, colocar no centro da vida de fé a experiência de Deus de Jesus antes que as propostas dogmáticas e/ou morais da instituição (CAROZZO, 1994, p. 24). 
Por isso uma fé sem raízes profundas na interioridade, que não é personalizada, encontrará muita dificuldade em evitar os riscos da redução a um conjunto de crenças, a um conhecimento religioso muito bem organizado, mas não sustentado ou alimentado por uma experiência espiritual.

Por outro lado, uma fé que redescobre seu estatuto místico claramente não pretenderá ser uma alternativa excludente à dimensão doutrinal, nem poderá cair em um raso subjetivismo. É apenas no bojo de uma experiência espiritual que as verdades de fé poderão iluminar desde dentro, com sabor, significação, vitalidade e fertilidade. Assim, a mística não será letra que mata, mas espírito que vivifica (CAROZZO, 1994).

\section{Mística e desejo de comunhão com a dor humana}

Uma das grandes críticas e suspeitas lançadas sobre a mística é o seu risco de ser algo alienante, que facilite a evasão da dureza da realidade, que proporcione àquele ou àquela que faz essa experiência uma válvula de escape para não ter que aderir à opacidade da história, com suas dores e sofrimentos. Pelo contrário, parece-nos, todas as correntes contemplativas da história da humanidade, todas as escolas de meditação e contemplação são escolas onde se vive o aprendizado de ver e escutar; mais ainda, de afinar a visão e a escuta para poder captar o real em toda a sua amplitude e profundidade.

E esse escutar e ver é não apenas ver e escutar sua própria interioridade, seus próprios desejos, seus próprios sentimentos espirituais, mas escutar os clamores da realidade, os sofrimentos do próximo, a realidade dolente do mundo. Ou seja, a mística é algo que, ao contrário de proporcionar fuga do sofrimento e da morte, dos problemas e conflitos, leva a mergulhar dentro deles e abraçá-los compassivamente, com profundo desejo de solidariedade e comunhão (MARDONES, 2005, p. 210). 
A revolução mística, - acontecendo no interior, na intimidade do coração humano - não é inimiga do compromisso político, da encarnação na realidade como muitas vezes foi acusada de se-lo. Ao contrario, em muitas partes do mundo se constatou nas ultimas décadas que muitos dos que se encontravam mergulhados de cheio em uma militância que havia perdido a conexão com suas motivações orantes e celebrativas acabavam abandonando igualmente a militância por perder o sentido pelo qual agiam e lutavam (ANDRADE, 2001a; 2001b).

A experiência mística, pelo contrário, leva a pessoa a enfrentar-se consigo mesma e sua tremenda solidão. Contesta a sociedade consumista e evasiva que se detém em uma configuração vital de espetáculo e exterioridade superficial. Faz com que o ser humano se defronte consigo mesmo por inteiro, inclusive com as dimensões mais sombrias de sua personalidade. E o torna consciente de sua capacidade humana para enfrentar estas dimensões e integrá-las (MARDONES, 2005, p. 211).

A autêntica experiência mística é na verdade um baluarte e uma garantia diante dos reducionismos antropológicos que proliferam em uma cultura consumista e "light". Contesta e desmente esses reducionismos e efetua uma real e consistente critica da sociedade tal como hoje está concebida e estruturada. É na verdade uma experiência e uma vivencia contracultural. E o testemunho mais palpável disso que afirmamos é o dado recorrente de que os místicos contemporâneos, longe de serem pessoas alienadas que escapam do mundo e se refugiam em uma estratosfera de gratificações sensíveis e catárticas, são ao contrario profundamente comprometidos com as lutas e os problemas de seu tempo. E sentem o apelo a assim proceder a partir da experiência do mistério que lhes abre a sensibilidade e os faz vulneráveis para tal.

Os escritos dos místicos contemporâneos, portanto, dão testemunho de que eles e elas, ao invés de fugir dos conflitos e sofrimentos dos quais seu ambiente e momento histórico estão cheios, sentem como seus, bem próximos a seu corpo e seu coração, todas as discussões pós-modernas sobre "a morte e o morrer, o 
sofrimento inocente, as experiências-limite, a alteridade radical e, positivamente, o Bem para alem do Ser." (TRACY, 2003, p. 242). Mais: tomam essas dolorosas realidades sobre si mesmos e no interior de seus corpos e suas vidas.

D. Tracy, na citação que acabamos de fazer, refere-se à filósofa e mística francesa Simone Weil quando pensa na consciência da presença de Deus inseparável do levar em conta a consciência humana e histórica do sofrimento inocente (TRACY, 2003, p. 242). ${ }^{24}$ Mais: faz notar que ela sugere - ainda que implicitamente - que se pode começar um processo místico a partir de um sentido trágico do sofrimento inocente. Esse sentido trágico, na vida de Simone, nunca foi separado da compaixão e do desejo de comunhão e participação, tal como o testemunha todo o seu processo vital (Cf. BINGEMER, 2009, p. 633-664; e tb. BINGERMER, 2011).

A experiência mística, portanto, nos tempos de hoje, pode começar muitas vezes pelos momentos apofáticos de sofrimento e cruz, experimentados diante do mal e do sofrimento injusto e inocente, e, apenas posteriormente, evoluir para o "sim" que - segundo Karl Barth no leito de morte, como diz D. Tracy - é a palavra final de um crente para todo grande "não" (TRACY, 2003, p. 243). O "sim" que os místicos contemporâneos dizem a Deus, que os chama e os habita, fazendo-lhes experimentar seu amor na verdade, começa para muitos místicos ali onde muitas vezes a Teodicéia encontrou uma aporia e homens grandes e brilhantes como Albert Camus não encontraram resposta a não ser a indignação e o anti-teísmo: no sofrimento do outro, sofrimento inocente e injusto que eles e elas desejam abraçar com paixão e compaixão.

Longe de ser um dolorismo masoquista, esse desejo que é critério de verificação da autenticidade da mística contemporânea abre as portas desde o fundo mais profundo da condição humana a um recordar (rememorar no coração) vital que guarda vivos na interioridade subjetiva e na história objetiva a memória

\footnotetext{
${ }^{24}$ Cf. o que diz S. Weil em seus textos «L' amour de Dieu et le malheur » (WEIL, 1950). Cf. tb. o admiravel texto «L' Illiade ou le poeme de la force» (WEIL, 1999, p. 540).
} 
subversiva de todo o sofrimento de muitas gerações, além de carregar no corpo as marcas desse sofrimento, não desejando estar separado dele. ${ }^{25}$

No desejo de comungar com a dor do outro, é o próprio mistério absoluto que, na pessoa do místico, vai ao encontro da dor humana. Assim fazendo, o místico passa da intimidade amorosa da câmara nupcial à praça publica onde estão em jogo os destinos humanos e se sofrem as dores e os conflitos de uma humanidade ainda não reconciliada (WEIL, 1950, p. 59).

A Revelação desse mistério, o místico a recebe e a interpreta. Geralmente o faz com a ajuda de outro ou de outra, - um mestre ou guia - a quem se confia espiritualmente. Por isso sua atitude não é apenas de submissão e respeito a uma vontade que se mostra como lei extrínseca e dura, mas sua pessoa inteira está convidada e, mais que isso, convocada, a transformar-se ela mesma em linguagem e prática de amor efetivo e concreto atravessado pela dor do outro.

O filósofo judeu E. Levinas - embora em nenhum momento diga estar falando da experiência mística - faz afirmações semelhantes ao aprofundar radicalmente aquilo que constitui o fundo mais profundo da condição humana. Com palavras de impressionante radicalidade, ele afirma, a subjetividade humana como "refém". Refém do outro e seu sofrimento: "O refém e o único culpado, pois sobre ele caíram todas as faltas e ele não pode nada senão se oferecer para carregar, sofrer, dar e expiar.” (LEVINAS, 1974, p. 140). Ao realizar isto, este mesmo refém assume configuração messiânica. E é de novo Levinas que afirma: "O Messias é o justo que sofre, que tomou sobre si o sofrimento dos outros... O fato de não se furtar à carga que impõe o sofrimento dos outros define a própria ipseidade. Todas as pessoas são Messias...O eu enquanto eu, tomando sobre si todo o sofrimento do mundo, se designa totalmente sozinho para este papel. Designar-se assim, não se furtar a ponto de responder antes que o chamado se faça ouvir, é isto precisamente ser eu. $\mathrm{O}$ eu é aquele que se promoveu a si mesmo para carregar toda a

\footnotetext{
${ }^{25}$ Citamos uma vez mais Simone Weil (1950, p. 325) por nos parecer ser quem melhor expressa o que afirmamos acima: "o santo tende a perfeição menos pela busca de integridade que por amor a Deus (ou ao divino) no ardor de uma fe que leva ao devotamento total e ao esquecimento de si."
} 
responsabilidade do mundo...E eis porque ele pode tomar sobre si todo o sofrimento de todos: ele não pode se dizer “ eu” senão na medida em que ele já tomou sobre si este sofrimento...E, concretamente, isto significa que cada um deve agir como se fosse o Messias. O Messianismo não é a certeza da vinda de um homem que detém a história. É meu poder de suportar o sofrimento de todos. É o instante onde reconheço este poder e minha responsabilidade universal."(LEVINAS, 1976, p. 120).

O que Levinas expõe em termos da Ética que, segundo ele, é a verdadeira e única filosofia, pode-se reconhecer na biografia de muitos místicos. Esta linguagem que diz do desejo de assumir e tomar sobre si a dor do outro; essa práxis amorosa de efetivamente dispor-se a fazê-lo, são e serão sempre, em sua essência, critério para verificar a verdade do encontro e da união com o mistério: a capacidade de integrar e de assumir a dor deste mundo como sua. Em suma: a compaixão.

\section{Conclusão: mística contemporânea - mística secular}

Após esse percurso, em que procuramos identificar o lugar da secularidade no mundo contemporâneo, como lugar de surgimento de autêntica experiência mística desinstucionalizada e destradicionalizada, vemos que, na verdade, é na experiência dos místicos que se pode encontrar o ponto culminante dessa interação.

Mergulhados em plena secularidade, homens e mulheres de várias latitudes demonstram que não é preciso fugir ou distanciar-se do secular para encontrar o divino. Mas, pelo contrário, em tempos em que a secularização é algo presente e ativo, configurando modelos sociais, políticos e mesmo religiosos, a experiência de Deus continua sendo possível e real.

Ela mostrará, porém, um rosto diferente. Não mais cercada e protegida pelo "religioso", encontrará no "século" seu lugar de acontecimento e a partir daí 
iluminará o tempo e o espaço dentro do qual é chamada a ser testemunha.

Pensadores como Alister Macgrath, Francis Collins, Ian Barbour e outros revelam a intrigante faceta de cientistas formados que não encontram contradição em professar a Fé e agir como cientistas. Como, por outro lado, percebe-se a experiência de Andre Comte-Sponville e Edward Wilson que, revelando-se não religiosos, encontram plausibilidade e valor no discurso e na experiência religiosa. Em seu discurso, pelo contrário, percebe-se uma atitude de respeito profundo por toda experiência verdadeira do mistério absoluto, seja chamado por que nome for. Reconhecem aí experiências falam da dimensão numinosa e transcendental do ser humano. Uma dimensão presente desde as origens da cultura e da civilização humana, como afirma Karen Armstrong em seu livro Em defesa de Deus, e que deve ser compreendida e respeitada como condição inalienável para a melhor identificação do fenômeno humano. (ARMSTRONG, 2011).

Já dirá um filósofo ateu contemporâneo de sensibilidade e consciência reta: "É o amor, não a esperança, que faz viver. É a verdade, não a fé que liberta... Estamos já no Reino: a eternidade é agora..." (COMTE SPONVILLE, 2008). "O amor... é que é verdadeiro (ele só é absoluto se amamos de verdade). É o Pentecostes dos ateus, ou o verdadeiro espírito do ateísmo: não o Espírito que desce, mas o espírito que se abre (para o mundo, para os outros, para a eternidade disponível) e que se regozija. Não é o absoluto que é amor; o amor é que, às vezes, nos abre para o absoluto. Pelo que a ética nos conduz à espiritualidade, mas sem ser suficiente, assim como a espiritualidade nos conduz à ética, mas sem tomar o lugar desta.” (COMTE SPONVILLE, 2007, p. 190). 


\section{REFERÊNCIAS}

AMARAL, Leila. et alii. Nova Era. Um desafio para os cristãos. São Paulo : Paulinas, 1994.

ANDRADE, Paulo Fernando Carneiro de. A crise da modernidade e as possibilidades de uma nova militância cristã. Iser Assessoria, Rio de Janeiro, 2001b. Disponível em: <http://www.iserassessoria.org.br/novo/produtos/individuais.php>. Acesso em: 01 mar. 2011.

ANDRADE, Paulo Fernando Carneiro de. Encantos e desencantos: a militância do cristão em tempos de crise. Iser Assessoria, Rio de Janeiro, 2001a. Disponível em:

<http://www.iserassessoria.org.br/novo/produtos/individuais.php >. Acesso em: 01 mar. 2011.

ARMSTRONG, K. Em defesa de Deus. São Paulo: Companhia das Letras, 2011.

BATAILLE, G. O erotismo. São Paulo: Arx, 2004.

BERTELLI, G. Mística e compaixão. A teologia do seguimento de Jesus em Thomas Merton. São Paulo: Paulinas, 2008.

BINGEMER, M. C. Alteridade e vulnerabilidade. Experiência de Deus e pluralismo religioso no moderno em crise. São Paulo: Loyola, 1993.

BINGEMER, M. C. O mistério e o mundo. Rio de Janeiro: Rocco, 2013.

BINGEMER, M. C. Simone Weil. Une mystique pour Le XXeme siecle. In: DELSOL, Chantal. (Org.). Simone Weil. Les Cahiers d'Histoire de la Philosophie. 1 ed. Paris: Editions du Cerf, 2009. p. 633-664.

BINGEMER, M. C. Simone Weil et Albert Camus. Sainteté sans Dieu et mystique sans Eglise. Cahiers Simone Weil, Paris, França, v. 28, n. 4, p. 365-386, 2005 a.

BINGEMER, M. C. Simone Weil: mística de la pasión y de la compasión. Buenos Aires: Ciudad Nueva, 2011 (tradução brasileira no prelo por EDUSC, 2014).

BINGEMER. M. C. Um rosto para Deus? São Paulo: Paulus, 2005b.

BINGEMER, M. C. (Org.). O impacto da modernidade sobre a religião. São Paulo: Loyola, 1990.

BOFF, C. Teoria do método teológico. Petrópolis: Vozes, 1998.

BURITY, J. Religião e politica na fronteira: desinstitucionalização e deslocamento numa relação historicamente polêmica. Rever, Revista de estudos da religião, São Paulo, n. 4, p. 27-45, 2001. 
CAROZZO, C. Spirituality in the New Age of Recolonization. Concilium, London, n. 4, p. 27-35 1994.

CAVANAUGH, William. Etre consommé. Une critique chrétienne du consumerisme. Paris: Editions de l' homme nouveau, 2007.

CHAMPION, F. La nébuleuse mystique-esotérique. Orientations psyco-religieuses des courants mystiqus et ésotériques contemporaines. In : CHAMPION, F. ; HERVIEU-

LEGER, D. (Org.). De l'émotion en religion. Renouveau et traditions. Paris: Centurion, 1990.

COLLINS, F. S. A linguagem de Deus. São Paulo: Gente, 2007.

COMTE SPONVILLE, A. L'esprit de l'athéisme. Paris: Cerf, 2006.

COMTE-SPONVILLE, A. O espírito do ateísmo. Introdução a uma espiritualidade sem Deus. São Paulo: Martins Fontes, 2008.

COMTE-SPONVILLE, A. O espírito do ateísmo. Introdução a uma espiritualidade sem Deus. São Paulo: Martins Fontes, 2007.

COMTE-SPONVILLE, A. O espírito do ateísmo. Para uma espiritualidade sem Deus. São Paulo: Martins Fontes, 2006.

CUNNINGHAM, L. S. Authority and Religious Experience. In: CUNNINGHAM, L. S. Spirituality and religious experience. The Way Supplement 92. London : The Way, 1998.

DANESE, A.; NICOLA, G. P. di,. Ignazio Silone. Percorsi di una conscienza inquieta. Torino: Effatà, 2007.

DAWKINS, Richard. Deus, um delírio. São Paulo: Companhia das Letras, 2007.

DAY, D. The Long Loneliness. Chicago: Saint Thomas More Press, 1993.

DELBREL, M. Euvres Complètes. Paris: Nouvelle Cité, 2007.

DERRIDA, J; VATTIMO, G. (Org.). A religião. São Paulo: Estação Liberdade, 2000.

DUCQUOC, Ch. L’ unique Christ. La symphonie differée. Paris: Cerf, 2002.

DUPUIS, Jacques. Rumo a uma teologia cristã do pluralismo religioso. São Paulo: Paulinas, 1999.

DURAND, Gilbert. A imaginação simbólica. Lisboa: Ed. 70, 1995.

ELIADE, Mircea. Briser le toit de la maison. La creativite et ses symbols. Paris: Gallimard, 1982. 
ELIADE, Mircea. Myth and reality. New York: Harper and Row, 1963.

ELIADE, Mircea. The sacred and the profane. New York: Harcourt, 1959.

ELIADE, Mircea. The two and the one. New York: Harper and Row, 1962.

FORTE, B. Trindade para ateus. São Paulo: Paulinas, 1999.

GAUCHET, Marcel. Un monde desenchanté? Paris: L' Atelier, 2004.

GONZÁLES BUELTA, B. Caminar sobre las águas. Santander: Sal Terrae, 2010.

GORMAN, Michael John Gorman. STS 102: "Leonardo: Science, Technology, and Art" at Stanford University, Fall 2002. History - Leonardo's vitruvian man. Disponível em: <http://leonardodavinci.stanford.edu/submissions/clabaugh/history/leonardo.html >. Acesso em: 01 fev. 2011.

GUILLEBAUD, J. C. La tyrannie du plaisir. Paris: Seuil, 1998.

HABERMAS, J. A mudança estrutural da esféra pública. Rio de Janeiro: Tempo Brasileiro, 1984.

HARRIS, Sam. Carta a uma nação cristã. São Paulo: Companhia das Letras, 2008.

HEBRARD, Monique. Entre Nova Era e Cristianismo. São Paulo: Paulinas, 1997.

HEISSIG, J. Diálogos a una pulgada del suelo. Recuperar las creencias en una época interreligiosa. Barcelona: Herder, 2005.

HEISSIG, J. The recovery of the senses: against the asceticisms of the age. Journal of Ecumenical Studies, Philadelphia, v. 33, n. 2, p. 216-237, 1996.

HERVIEU-LEGER, D. La religion pour mémoire. Paris: Cerf, 1993.

HILLESUM, Etty. Une vie bouleversée. Paris: Seuil, 2008.

HILLESUM, Etty. Une vie bouleversee, suivi de Lettres de Westerbork. Paris: Seuil, 1995.

HITCHENS, Christopher. Deus não é grande. Como a religião envenena tudo. Rio de Janeiro: Ediouro, 2007.

LABARRIÈre, J. P. L'homme et l'Absolu I. Archives de Philosophie, Paris, v. 36 , p. 209-223, 1973

LACOSTE, Jean Yves (Org.). Dictionnaire critique de théologie. Paris: PUF,1998.

LE SAUX, H. La montée au fond du cœur. Paris: O.E.I.L., 1986. 
LESTE Europeu lidera índice de suicídios. DW. Notícias. Alemanha. 08.08.2002.

Disponível em: <http://www.dw-world.de/dw/article/o,,605532,0o.html>. Acesso em: 25 fev. 2011.

LEVINAS. E. Autrement qu' etre ou au dela de l' essence. La Haye: Martinus Nijhoff, 1974 .

LEVINAS. E. Autrement qu'être ou au-delà de l'essence. La Haye: Martinus Nijhoff, 1974.

LEVINAS. E. Difficile Liberté. Paris: Albin Michel, 1976.

LEVINAS. E. Ethique comme philosophie première. Paris: Rivages, 1998.

LEVINAS. E. Liberté et commandement. Saint Clément de rivière: Fata Morgana, 1994.

LIBANIO, J. B. ; MURAD, A. Introdução à teologia. Perfil, enfoques, tarefas. São Paulo: Loyola, 1996.

MACMILLAN Publishing Company. The Encyclopedia of Religion, a division of Macmillan, Inc., . Electronic edition produced by Infobases, Inc. Provo: Utah, 1987, 1995.

MAITRE, J. Les deux côtés du miroir. Note sur l'évolution religieuse actuelle de la population française par rapport au catholicisme. L’Année Sociologique, Paris, v. 38, N. 3, p. 28-43, 1988.

MARDONES, J. M. La transformación de la religión. Madrid: PPC, 2005.

MARDONES, J. M. Para compreender las nuevas formas de la religión. La reconfiguración postcristiana de la religión. Estella/Navarra: Verbo Divino, 1994.

MARITAIN, J. R. CEuvres Complètes. Paris: Editions Universitaires, 1995.

MARTELLI, S. A religião na sociedade pós-moderna. São Paulo: Paulinas, 1995.

MASSIGNON, L. Parole donnée. Paris: Julliard, 1962.

MC GINN, Bernard. The foundations of mysticism, New York: Crossroad, 1992 (trad. Bras. As fundações da mística. São Paulo: Paulus, 2012).

McDONNELL, K. Spirit and experience in Bernard of Clairvaux, Theological Studies, Thousand Oaks, v. 58, n. 1, p. 3-18, 1997.

MERTON, Thomas. The Seven Storey Mountain. New York: Harcourt, Brace, 1948.

MOLTMANN, Jurgen. God for a secular society. The public relevance of Theology, Minneapolis: Fortress Press, 1999. 
MORANO, Carlos Dominguez. Los registros del deseo - Del afecto, el amor y otras pasiones. Bilbao: Desclée de Brouwer, 2001.

MOUNIER, E. L'engagement de la foi. Seuil. Paris: Les Presses universitaires de France,1968.

MOUNIER, E. Le personnalisme. 7 ed. Paris: Les Presses universitaires de France, 1961.

ONFRAY, Michel. Tratado de ateologia. São Paulo: Martins Fontes, 2007.

PACE, E. Religião e globalização. In: ORO, A. P.; STEIL, C. A. (Org.). Globalização e religião. Petrópolis: Vozes, 1997. p. 25-42.

PARKER, C. Globalização e religião: o caso chileno. In: ORO, A. P.; STEIL, C. A. Globalização e religião. Petrópolis: Vozes, 1997. p.156-171.

POUPARD, Paul (Org.). Diccionario de las Religiones. Barcelona: Herder, 1987.

QUEIRUGA, Andrés Torres. Fin del cristianismo premoderno. Retos hacia un nuevo horizonte. Santander: Sal Terrae, 2000.

QUEIRUGA, Andrés Torres. Creio em Deus Pai. O Deus de Jesus como afirmação plena do humano. São Paulo: Paulinas, 1993.

RAHNER, K. Los cristianos anónimos. Escritos de Teología, VI, Barcelona: Herder, 1996.

RAHNER, Karl. A exigência de uma "fórmula breve" da fé cristã. Concilium - Revista Internacional de Teologia, São Paulo: Herder, n. 3, p. 62-73, mar. 1967.

RAHNER, Karl. Curso fundamental da Fé. São Paulo: Paulinas, 1989.

RICOEUR,Paul. L’herméneutique de la sécularisation. Foi, idéologie, utopie. In : CASTELLI, E. (Ed.). Actes d'un colloque organisé par le Centre International d'Études Humanistes et par l'institut d'Études Philosophiques de Rome. Paris, Aubier, 1976. p.49-68

RUIZ DE LA PEÑA, Juan Luis. El don de Dios. Antropologia teológica. Sal Terrae: Santander, 1991.

SANCHIS, P. O campo religioso contemporâneo no Brasil. In: ORO, A. P.; STEIL, C. A. (Org.). Globalização e religião. Petrópolis: Vozes, 1997. p. 103-146.

SARTRE, J. P. Entre Quatro Paredes - Huis Clos. Rio de Janeiro: Civilização Brasileira, 1975 .

SCHLEGEL, Jean Louis. Retour du religieux et christianisme. Quand de vieilles croyances redeviennent nouvelles. Études, Paris, v. 362, n. 1, p. 89-104, jan. 1985. 
SCHOLEM, Gershom. Mysticism and Society. Diogenes, [s.l], n. 58, p. 1-24, 1967.

SCHOLEM, Gershom. Religious Authority and mysticism. In: SCHOLEM, Gershom. On the Kabbalah: New perspectives. New Haven: Yale University Press, 1988. cap 1.

SCHOLEM, Gershom. The major trends in jewish mysticism. New York: Schocken, 1961 (trad. bras. Ed. Objetiva: Rio de Janeiro, 1972).

SIQUEIRA, D. Pluralidade e transito religioso na atualidade. Disponível em: <http://bmgil.tripod.com/sde47.html>. Acesso em: 26 fev. 2011.

SOUZA, L. A. Gomez de. Secularização en declínio e potencialidade transformadora do sagrado. (Religião e movimentos sociais na emergência do homem planetário). Síntese, Belo Horizonte, v. 13, n. 37, p. 33-49, 1986b.

SOUZA, L. A. Gomez de. Secularização en declínio e potencialidade transformadora do sagrado. Religião e movimentos sociais na emergência do homem planetário. Religião e sociedade, Rio de Janeiro, v. 13, n. 2, p. 2-16, jul. 1986a.

TEIXEIRA, F. A experiência de Deus nas religiões. Numen, Juiz de Fora, v. 3, n. 1, p, 111148, jan-jun 2000.

TEIXEIRA, F. Teologia das religiões. Uma visão panorâmica. São Paulo: Paulinas, 1995 .

TOURAINE, Alain. Um novo paradigma. Petropolis: Vozes, 2006.

TRACY, D. Afterword. In: KESSLER, M; SHEPPAR, Ch. (Ed) Mystics. Presence and aporia. Chicago/London: The University of Chicago Press, 2003.

VELASCO, Juan Martín .et alii. La interioridad: un paradigma emergent. Madrid: PPC, 2004 .

VELASCO, Juan Martín. A experiência cristã de Deus. São Paulo: Paulinas, 1994.

WEIL, Simone. L' Illiade ou le poeme de la force. In: WEIL, Simone. Oeuvres. Paris: Gallimard, 1999. coll. «Quarto». p. 527-552

WEIL, Simone. L' amour de Dieu et le malheur. In: WEIL, Simone. Attente de Dieu. Paris: La Colombe, 1950. p. 76-90.

WEIL, Simone. La Connaissance Surnaturelle. Paris: Gallimard,1950. coll. < Espoir >

WESTHELLE, V. Modernidade, mito e religião. Crítica e reconstrução das representações religiosas. Numen, Juiz de Fora, v. 3, n. 1, p. 11-38, jan-jun 2000. 